\title{
Sphingosine kinase 1 promotes tumor progression and confers malignancy phenotypes of colon cancer by regulating the focal adhesion kinase pathway and adhesion molecules
}

\author{
SHI-QUAN LIU, YING-JIE SU, MENG-BIN QIN, YE-BO MAO, JIE-AN HUANG and GUO-DU TANG \\ Department of Gastroenterology, First Affiliated Hospital of Guangxi Medical University, \\ Nanning, Guangxi Autonomous Region 530021, P.R. China
}

Received October 8, 2012; Accepted November 16, 2012

DOI: $10.3892 /$ ijo.2012.1733

\begin{abstract}
Studies suggest a tumor-promoting function of sphingosine kinase 1 (SphK1) in some types of human tumors, however, its effect on colon cancer is still unclear. The aims of this study were to investigate the roles of SphK1 in the progression and tumor cell phenotypic changes in colon cancer. Moreover, the focal adhesion kinase (FAK) pathway and the expression of intercellular adhesion molecule-1 (ICAM-1) and vascular cell adhesion molecule-1 (VCAM-1) were detected to explore the mechanisms of SphK1 action. In this study, the expression of SphK1, FAK and phospho-FAK (p-FAK) was analyzed in 66 surgical specimens of primary colon cancer and matched adjacent normal tissues by immunohistochemistry and western blotting. In addition, N,N-dimethylsphingosine (DMS), SphK1 DNA and shRNA transfection were used to regulate the expression and activity of SphK1 in the LOVO colon cancer cell line. Tumor cell phenotypic changes were analyzed by cell viability, invasion and apoptosis assays. Results showed that the expression of SphK1, FAK and p-FAK in colon cancer tissues were significantly stronger compared to those in matched normal tissues. There was a close correlation between the expression of SphK1 and FAK or p-FAK and the co-expression of SphK1, FAK and p-FAK significantly associated with histological grade, Dukes' stage, lymph node metastasis and distant metastasis. Overexpression of SphK1 after DNA transfection enhanced tumor cell viability and invasiveness, but suppressed cell apoptosis. In contrast, suppression of SphK1 by DMS and shRNA reduced tumor cell viability and invasiveness, but promoted cell apoptosis. The expression of FAK, p-FAK, ICAM-1 and VCAM-1 in LOVO cells were increased with the
\end{abstract}

Correspondence to: Dr Jie-an Huang, Department of Gastroenterology, First Affiliated Hospital of Guangxi Medical University, 6 Shuangyong Road, Nanning, Guangxi Autonomous Region 530021, P.R. China

E-mail: jh23229@gmail.com

Key words: sphingosine kinase 1, colon cancer, progression, malignancy phenotype, focal adhesion kinase, adhesion molecule overexpression of SphK1 but decreased with the suppression of SphK1. These findings indicate that SphK1 regulates tumor cell proliferation, apoptosis and invasion, which ultimately contributes to tumor progression and malignancy phenotype in colon cancer. FAK pathway, ICAM-1 and VCAM-1 may play critical roles in this SphK1-mediated effect.

\section{Introduction}

Colon cancer is one of the most common causes of cancerrelated mortality worldwide, it continues to be a major health concern in the world (1). Although recent data have elucidated some of the molecular mechanisms of tumor pathogenesis and progression, the etiology of colon cancer is largely unknown. The development, progression and malignancy phenotypes of colon cancer may be resulted from a complex set of genetic events that promotes cell proliferation, survival and invasion.

Sphingosine kinase ( $\mathrm{SphK}$ ) is a conserved lipid kinase that catalyzes the phosphorylation of sphingosine to form sphingosine-1-phosphate (S1P). SphK is a critical regulator of sphingolipid-mediated functions. Up to now, two mammalian isozymes, SphK1 and SphK2, have been characterized. It is widely accepted that SphK1 resides at the centre of a cell-survival rheostat that balances the cellular levels of pro-apoptotic ceramide with anti-apoptotic S1P $(2,3)$. Evidence also showed that SphK1 enhances cancer cell migration by secretion of S1P in a protein kinase $\mathrm{C}-\alpha$ - and ERK1/2-dependent manner (4). SphK1 appeared upregulated in some solid tumors, high level of SphK1 was associated with poor survival of tumor patients (5) and suppressing SphK1 reduced tumor growth in animal model (6). SphK1 was significantly elevated in azoxymethane-induced murine colon cancer tissues, SphK1 knockout mice subjected to azoxymethane had significantly less aberrant formation of crypt foci and cancer development (7). Moreover, SphK1 inhibitor or shRNA enhanced the cytotoxicity and chemosensitivity of colon cancer cells $(8,9)$. Studies also showed that the expression of SphK1 was required for the proliferation of small intestinal tumor cell and SphK1 was able to promote intestinal adenoma progression (10). Therefore, SphK1 may play an important role in the carcinogenesis and metastasis of gut tumors. 
Focal adhesion kinase (FAK) is a non-receptor tyrosine kinase that acts as a primary regulator of focal adhesion signaling to regulate cell survival, adhesion and migration, which are key processes for a transformed cell to become invasive and metastatic (11). Numerous studies had reported FAK overexpression in various tumor cells, including gastrointestinal tract cancer, and its expression correlated with tumor malignancy (12). LPA induced FAK redistribution and activation in confluent monolayer colon cancer Caco-2 cells conferring a migratory phenotype (13). Lunasin inhibited metastasis of human colon cancer cells by suppressing FAK signaling pathway and potentiated the effect of oxaliplatin in preventing the outgrowth of metastasis (14). FAK signaling pathway may play an important role in keeping the malignancy phenotypes of colon cancer cells. However, the regulating mechanism of SphK1 and FAK and the events following SphK1 and FAK activation in colon cancer are still needed to be explored.

Mechanistic studies suggest a relation of SphK1/S1P to the regulation of FAK. It was reported that S1P induced a rapid increase in tyrosine phosphorylation of FAK and stimulated motility of human endothelial cells $(15,16)$. Evidence was presented that activation of FAK pathway was involved in the cell proliferation induced by S1P in human prostate cancer cells (17). It seems reasonable to hypothesize that SphK1 may promote the progression and confer malignancy phenotype of colon cancer through mediating the expression of FAK. In the present study, the correlations of SphK1, FAK and p-FAK expression with clinicopathologic parameters were investigated in colon cancers and paired normal tissues. SphK1 inhibitor N,N-dimethylsphingosine (DMS), SphK1 DNA and SphK1 shRNA transfection were exploited to confirm the effect of SphK1 on malignancy phenotypes in colon cancer LOVO cells. In addition, effects of SphK1 on FAK, p-FAK, intercellular adhesion molecule-1 (ICAM-1) and vascular cell adhesion molecule-1 (VCAM-1) were determined to explore the molecular mechanisms.

\section{Materials and methods}

Tissue specimens. Sixty-six fresh colon cancer tissues and matched normal tissues from patients were collected and fresh-frozen in liquid nitrogen after surgical resections performed at the First Affiliated Hospital of Guangxi Medical University (Guangxi, China) from 2009 to 2010. For the 66 fresh tissues, one-half of the tissue was snap-frozen immediately in liquid nitrogen and stored at $-80^{\circ} \mathrm{C}$ and the other half was formalin-fixed and paraffin-embedded. Each case was reviewed by 2 experienced histopathologists who were blinded to disease status. The patients had not received chemotherapy or radiation therapy before tumor resection. The study was approved by the Institutional Ethics Committee of Guangxi Medical University under full consideration of the declaration on human rights of Helsinki.

Immunohistochemistry staining. Formalin-fixed, paraffinembedded tissue blocks were serially sectioned at $4 \mu \mathrm{m}$. Sections were deparaffinized in xylene and rehydrated before analysis. Endogenous peroxidase was quenched with $3.0 \%$ hydrogen peroxide in methanol for $10 \mathrm{~min}$, antigen retrieval was performed by microwave for $15 \mathrm{~min}$ and tissue sections were blocked with normal rabbit serum for $20 \mathrm{~min}$. This was followed by incubation overnight at $4^{\circ} \mathrm{C}$ with mouse monoclonal FAK (Santa Cruz Biotechnology, Inc., Santa Cruz, CA, USA), rabbit polyclonal p-FAK (Abcam, Cambridge, UK) and mouse monoclonal SphK1 (Sigma-Aldrich, St Louis, MO, USA) primary antibody. Sections were washed with PBS and incubated with second antibody at room temperature for $30 \mathrm{~min}$. After being washed with PBS, sections were stained by a streptavidin-peroxidase detection system. Antibody binding was visualized using diaminobenzidine as chromogen and counterstained with hematoxylin. Incubation with PBS instead of the primary antibody served as a negative control.

The degree of staining was estimated by semiquantitative evaluation and categorized by the extent and intensity of staining as follows: i) The extent of positive cells was scored as: 0 , positive-staining cells $<5 \%$; 1 , positive-staining cells $5-25 \% ; 2$, positive-staining cells $26-50 \%$; 3 , positive-staining cells $51-75 \%$; 4 , positive-staining cells $>75 \%$. ii) The intensity of staining was scored as: 0, achromatic; 1, light yellow; 2, yellow; 3 , brown. The percentage of positive tumor cells and staining intensity were multiplied to produce a weighted score for each case. Cases with weighted scores $\leq 1$ were defined as negative; otherwise as positive.

Cell culture and transfection. Human colon cancer LOVO cell line was obtained from ATCC. Cells were cultivated in DMEM high glucose medium (Invitrogen Co., Carlsbad, CA, USA) supplemented with 10\% FBS (Gibco-BRL, Rockville, MD, USA) and antibiotics (100 U/ml penicillin plus $50 \mathrm{mM}$ streptomycin, Invitrogen Co.) in an atmosphere of $5 \% \mathrm{CO}_{2}$ at $37^{\circ} \mathrm{C}$.

In order to develop a new model system to better study effects of SphK1 on cell proliferation, apoptosis and invasion, LOVO cells were transfected with SphK1 DNA (SphK1 group), SphK1 shRNA (shRNA group) and SphK1 non-targeting shRNA control (NC group). In brief, $24 \mathrm{~h}$ before transfection, cells were cultivated in medium without antibiotics. Cells were seeded in 6 -well plates $\left(2 \times 10^{5}\right.$ cells/well $)$. The shRNA, non-targeting shRNA control (NC) or DNA plasmid targeting SphK1 (Shanghai GenePharma Co., Ltd., Shanghai, China) were diluted in Opti-MEM ${ }^{\circledR}$ (Gibco-BRL) Reduced Serum Medium without serum. Cells were transfected with $40 \mathrm{nmol}$ shRNA oligomer, NC or $0.8 \mu \mathrm{g}$ of DNA using Lipofectamine ${ }^{\mathrm{TM}}$ 2000 reagent (Life Technology Co., Carlsbad, CA, USA) according to the manufacturer's instructions. Cells were harvested $48 \mathrm{~h}$ later for the following experiment.

SphK1 activity assay. Cells were cultured in a culture dish. Cells were transfected with SphK1 shRNA, NC, SphK1 DNA or treated with $50 \mu \mathrm{M}$ DMS (Merck KGaA, Darmstadt, Germany) for $24 \mathrm{~h}$ (DMS group). Cells treated with equal amount of $0.9 \% \mathrm{NaCl}$ instead of drugs served as the control group. Activation of SphK1 was measured as described previously with slight modification (18). Cells were resuspended in ice-cold $0.1 \mathrm{M}$ phosphate buffer [( $\mathrm{pH} 7.4)$ containing 20\% glycerol, $1 \mathrm{mM}$ mercaptoethanol, $1 \mathrm{mM}$ EDTA, phosphatase inhibitors $1 \mathrm{mM}$ sodium orthovanadate, $15 \mathrm{mM}$ sodium fluoride], protease inhibitors $(10 \mu \mathrm{g} / \mathrm{ml}$ leupeptin, aprotinin, trypsin, chymotrypsin and $1 \mathrm{mM}$ phenylmethylsulfonylfluoride) and $0.5 \mathrm{mM} 4$-deoxypyridoxine, were then disrupted by 
three 5-sec pulses with a Fisher 550 sonic dismembranator. Each sample containing $100 \mu \mathrm{g}$ protein was assayed for sphingosine kinase activity by incubation with sphingosine and $\left[\gamma-{ }^{32} \mathrm{P}\right]$-ATP (Beijing Free Biotech. Co., Beijing, China) for $30 \mathrm{~min}$ at $37^{\circ} \mathrm{C}$. Products were separated on TLC on Silica Gel G60 (Merck KGaA) using 1-butanol/methanol/acetic acid/water (80:20:10:20) and visualized by autoradiography. The radioactive spots corresponding to sphingosine phosphate were scraped and counted in a scintillation counter.

Cells viability assay. Cell viability was determined by colorimetric assay utilizing MTT (Sigma-Aldrich). In brief, non-transfected LOVO cells (DMS group), cells of SphK1, shRNA and NC group were seeded in 96 -well plate $\left(5 \times 10^{3}\right.$ per well) as different experimental groups. Cells of DMS group were incubated with 25, 50 and $100 \mu \mathrm{M}$ DMS for $0,6,12$ and $24 \mathrm{~h}$. LOVO cells treated with equal amount of $0.9 \% \mathrm{NaCl}$ instead of drugs served as the control group. Then $20 \mu \mathrm{l} \mathrm{MTT}$ solution $(5 \mathrm{mg} / \mathrm{ml})$ was added to each well and incubated at $37^{\circ} \mathrm{C}$ for $4 \mathrm{~h}$. The solution was carefully removed, followed by addition of $150 \mu \mathrm{l}$ dimethyl sulfoxide (DMSO, Invitrogen Co.) to each well to solubilize MTT. The absorbance $(A)$ of sample was measured at $490 \mathrm{~nm}$ and the cell viability was expressed as $A$ value of experimental cells/control cells x $100 \%$. Triplicate measurements were done at each time-concentration.

Flow cytometry analysis. The treatment of cells was the same as in the SphK1 activity assay. Cells were harvested and washed twice with PBS. The cells were resuspended in $500 \mu \mathrm{l}$ binding buffer at a density of $1 \times 10^{6}$ cells/ml, $1 \mu 1$ Annexin V-FITC (Nanjing KeyGen Biotech. Co., Nanjing, China) was added to the sample and incubated for $20 \mathrm{~min}$ at room temperature in the dark, and then $5 \mu \mathrm{l}$ propidium iodine (PI) buffer was added and incubated for $5 \mathrm{~min}$ at $4^{\circ} \mathrm{C}$ in the dark. Finally, samples were evaluated by flow cytometry and data were analyzed using CellQuest (Becton-Dickinson, San Jose, CA, USA).

Semi-quantitative reverse transcription polymerase chain reaction. The cell treatment was the same as in the SphK1 activity assay. Total-RNAs were extracted from tissue samples or cells using TRIzol reagent (Invitrogen Co., San Diego, CA, USA). First-strand cDNA was synthesized from $1 \mu \mathrm{g}$ of total-RNA using oligo-dT primer and Moloney murine leukemia virus reverse transcriptase (Fermentas International Inc., Burlington, Canada) according to the instructions from the manufacturers. Then cDNA was amplified by using the following primers: SphK1, 5'-ATG CAC GAG GTG GTG AAC G-3' (sense), 5'-GGA GGC AGG TGT CTT GGA AC-3' (antisense), FAK: 5'-ACC TCA GCT AGT GAC GTA TGG-3' (sense), 5'-CGG AGT CCC AGG ACA CTG TG-3' (antisense), $\beta$-actin: 5'-AGC CAT GTA CGT AGC CAT CC-3' (sense), 5'-CTC TCA GCT GTG GTG GTG AA-3' (antisense). The PCR products were analyzed on $2 \%$ agarose gels and visualized by ethidium bromide staining. Quantitation of expression levels was achieved after adjustment for the expression levels of $\beta$-actin by densitometry. A 100-base pair DNA ladder was used as a molecular weight marker on each gel.

Western blot analysis. The treatment of cells was the same as in the SphK1 activity assay. Tissue samples or cells of different groups were lysed in lysis buffer [50 mM Tris (pH 7.4), $150 \mathrm{mM} \mathrm{NaCl}, 1 \%$ Triton $\mathrm{X}-100,1 \%$ sodium deoxycholate, $0.1 \%$ SDS, $2 \mathrm{mM}$ sodium pyrophosphate, $25 \mathrm{mM} \beta$-glycerophosphate, $1 \mathrm{mM}$ EDTA, $1 \mathrm{mM} \mathrm{Na} \mathrm{VO}_{4}$, $0.5 \mu \mathrm{g} / \mathrm{ml}$ leupeptin and $1 \mathrm{mM}$ PMSF] and then the lysate was incubated on ice for $30 \mathrm{~min}$ and centrifuged at $12000 \mathrm{rpm}$ for $10 \mathrm{~min}$. The supernatant was collected and the content of total protein was evaluated by the Bradford colorimetry. After denaturation, $40 \mu \mathrm{g}$ of protein from each sample was separated on a $12 \%$ SDS-PAGE and electroblotted onto nitrocellulose membrane. The nitrocellulose membrane was blocked with 5\% non-fat milk in TBST [10 mM Tris ( $\mathrm{pH} 7.4)$, $100 \mathrm{mM} \mathrm{NaCl}, 0.5 \%$ Tween 20] for $2 \mathrm{~h}$ at room temperature. Membrane was subsequently incubated overnight at $4^{\circ} \mathrm{C}$ in $5 \%$ non-fat milk in TBST containing either mouse monoclonal $\beta$-actin, mouse monoclonal FAK, mouse monoclonal ICAM-1, rabbit polyclonal VCAM-1 (Santa Cruz Biotechnology, Inc.) or rabbit polyclonal p-FAK (Abcam) antibody, followed by $1 \mathrm{~h}$ incubation with peroxidase-conjugated secondary antibody (Santa Cruz Biotechnology, Inc.). The protein signals were visualized using Pierce enhanced chemiluminescence (ECL) reaction Western Blotting Substrate (Pierce Co., Rockford, IL, USA) and exposed to medical X-ray film.

In vitro cell migration and invasion assay. The cell treatment was the same as in the SphK1 activity assay. Cell migration and invasion were evaluated in 24-well transwell chamber model. Briefly, the upper and lower culture compartments of each well were separated by polycarbonate membranes $(8-\mu \mathrm{m}$ pore size). To determine baseline migration ability, $1.0 \times 10^{5}$ cells in $0.2 \mathrm{ml}$ of complete medium containing $5 \%$ FBS were placed into the upper compartment of uncoated wells (Corning Costar Inc., Corning, NY, USA), and $0.6 \mathrm{ml}$ of complete medium containing $10 \%$ FBS were placed into the lower compartment. In parallel, to assess the ability of the cells to penetrate a collagen matrix (invasiveness), the experiment was repeated using the upper compartment coated with $100 \mu \mathrm{l} 5 \mu \mathrm{g} / \mathrm{ml}$ collagen matrix (Corning Costar Inc.). The transwell chambers were incubated for $24 \mathrm{~h}$ at $37^{\circ} \mathrm{C}$ in $95 \%$ air and $5 \% \mathrm{CO}_{2}$. Cell penetration through the porous membrane into the plate was detected by crystal violet staining, and then observed and photographed at x400 magnification on a light microscope. Data were quantitated by cell count and expressed as average of cell number from 4 random fields. The cell number indicates the cell migration capability and invasiveness.

Enzyme-linked immunosorbent assay (ELISA). The cell treatment was the same as in the SphK1 activity assay. The cell culture supernatant was collected for ICAM-1 and VCAM-1 analysis using ELISA detection kits (Life Technology Co.) according to the instructions from the manufacturers. In this experiment, blank wells (no sample or HRP-conjugate reagent), standard wells and testing sample well were set, $50 \mu$ ldiluted standard was added to standard wells, $40 \mu \mathrm{l}$ sample dilution and $10 \mu \mathrm{l}$ culture supernatants were added to test sample wells, mixing gently with shaking and incubated for $30 \mathrm{~min}$ at $37^{\circ} \mathrm{C}$. Discard liquid and washed each well with diluted washing liquid for 5 times. Then $50 \mu \mathrm{l} \mathrm{HRP-conjugate} \mathrm{reagent} \mathrm{was}$ added to each well, except the blank wells. Mixing gently with 

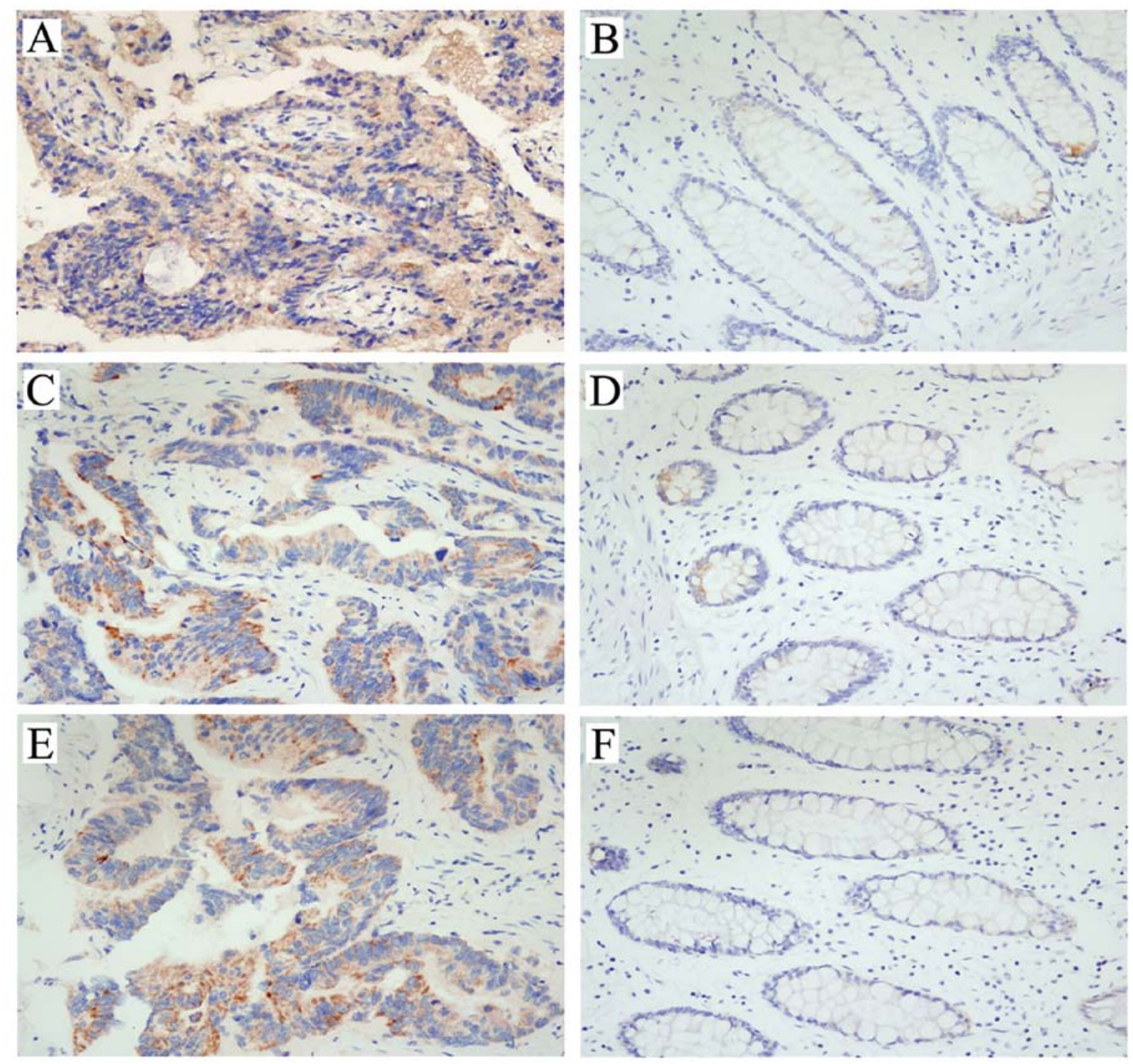

Figure 1. Immunohistochemistry analysis of SphK1, FAK and p-FAK. In this paired sample of primary colon cancer and normal colon mucosa from the same patient, intense (A) SphK1, (C) FAK and (E) p-FAK staining (x400 magnification) are demonstrated in the primary colon cancer. However, little detectable (B) SphK1 and (D) FAK expression (x400 magnification) is evident in the normal colon mucosa. As shown in F, p-FAK staining (x400 magnification) is absent in paired normal mucosa.

shaking, incubated for $30 \mathrm{sec}$ at $37^{\circ} \mathrm{C}$. Liquid was discarded followed by 5 washes. Chromogen solution A and B (50 $\mu 1$ each) were added to the wells, gently mixing, and incubated for $10 \mathrm{~min}$ at $37^{\circ} \mathrm{C}$. Then, $50 \mu 1$ stop solution was added to each well to stop the reaction. After zero setting, the $A$ value was measured at $450 \mathrm{~nm}$. According to standard concentration and the corresponding $A$ values, the standard curve linear regression equation was harvested, then the sample concentration was calculated according to the regression equation.

Statistical analysis. The significance between SphK1, FAK, p-FAK and clinicopathologic characteristics of the patients was assessed with the $\chi^{2}$ test. The correlation between SphK1, FAK and p-FAK was calculated by the method of Pearson's correlation coefficient. Data are presented as mean \pm standard deviation (SD) and Student's t-test were used to compare continuous variables among groups. A p-value of $<0.05$ was considered significant.

\section{Results}

Immunohistochemistry analysis of SphK1, FAK and p-FAK in colon cancer and matched normal colonic tissues. Immunohistochemistry staining for SphK1, FAK and p-FAK was revealed as yellow or brown color and present in the cytoplasm of colon cancer cells, and the staining of cancerous tissue was significantly stronger than that of matched normal tissue (Fig. 1). As shown in Table II, in 66 cancerous tissues, 48 (72.73\%) showed positive staining for SphK1, 51 (77.27\%) showed positive staining for FAK and 39 (59.09\%) showed positive staining for p-FAK. In 66 matched normal tissues, 23 (34.85\%) showed positive staining for SphK1, 15 (22.73\%) showed positive staining for FAK and 11 (16.67\%) showed positive staining for $\mathrm{p}-\mathrm{FAK}$, the positive staining rates were significantly lower than those of cancerous tissues $(\mathrm{p}<0.01)$. Moreover, there was a close correlation between the expression of SphK1 and FAK or p-FAK (Table I). The co-expression of 
Table I. The correlation between the protein expression of FAK, p-FAK and SphK1 in colon cancer tissues.

\begin{tabular}{|c|c|c|c|c|c|}
\hline \multirow[b]{2}{*}{ Expression } & \multicolumn{3}{|c|}{ SphK1 expression } & \multirow[b]{2}{*}{ Correlation } & \multirow[b]{2}{*}{ p-value } \\
\hline & Positive (\%) & Negative (\%) & Total & & \\
\hline \multicolumn{6}{|l|}{ FAK } \\
\hline Positive (\%) & $43(65.16)$ & $8(12.12)$ & $51(77.27)$ & 0.480 & 0.000 \\
\hline Negative (\%) & $5(7.58)$ & $10(15.15)$ & $15(22.73)$ & & \\
\hline \multicolumn{6}{|l|}{ p-FAK } \\
\hline Positive (\%) & $36(54.55)$ & $3(4.55)$ & $39(59.09)$ & 0.499 & 0.000 \\
\hline Negative (\%) & $12(18.18)$ & $15(22.72)$ & $27(40.91)$ & & \\
\hline
\end{tabular}

SphK1, FAK and p-FAK significantly associated with histological grade, Dukes' stage, lymph node metastasis and distant metastasis, but no correlation was found between SphK1, FAK, p-FAK expression and age or gender (Table II).

Western blot detection of SphK1, FAK and p-FAK in colon cancer and matched normal colonic tissues. The expression of SphK1, FAK and p-FAK was also detected in these 66 colon cancer specimens and matched normal colonic tissues using western blot analysis. The density of SphK1, FAK and p-FAK (Tyr 397) expression in cancerous tissues was much stronger than that in matched normal tissues (Fig. 2). The western blot analysis results fit very well with those obtained by immunohistochemistry.

Activity and mRNA expression of SphK1. Fig. 3 shows that SphK1 DNA transfection dramatically enhanced the mRNA expression of SphK1, shRNA knockdown significantly decreased the mRNA expression of SphK1 and NC transfection had no significant effect on the mRNA expression of SphK1. As shown in Fig. 4, LOVO cells possessed a basal activity of SphK1 (26.16 pmol/mg/min), SphK1 DNA transfection significantly enhanced the activity of SphK1 (65.19 $\mathrm{pmol} / \mathrm{mg} / \mathrm{min})$, SphK1 shRNA knockdown significantly suppressed the activity of SphK1 (6.28 pmol/mg/min) and NC had no significant effect on the activity of SphK1 (25.46 pmol/mg/min). Moreover, in cells treated with $50 \mu \mathrm{M}$ DMS for $24 \mathrm{~h}$, the SphK1 activity reduced to $5.31 \mathrm{pmol} / \mathrm{mg} / \mathrm{min}$.

SphK1 enhances tumor cell proliferation, migration and invasiveness while suppresses cell apoptosis. Overexpression of SphK1 dramatically enhanced the cell proliferation, migration and invasiveness (Figs. 5A and 7), and significantly suppressed cell apoptosis (Fig. 6). Compared with control group, SphK1 shRNA significantly suppressed the cell proliferation, cell migration and invasiveness (Figs. 5A and 7), while significantly promoted cell apoptosis (Fig. 6). DMS suppressed cell proliferation in a time- and dose-dependent manner (Fig. 5B), DMS significantly promoted cell apoptosis and suppressed cell migration and invasiveness (Figs. 6 and 7). NC transfection had no significant effect on cell biological behavior.

SphK1 enhances the expression of FAK and p-FAK in LOVO cells. Overexpression of SphK1 not only enhanced the mRNA

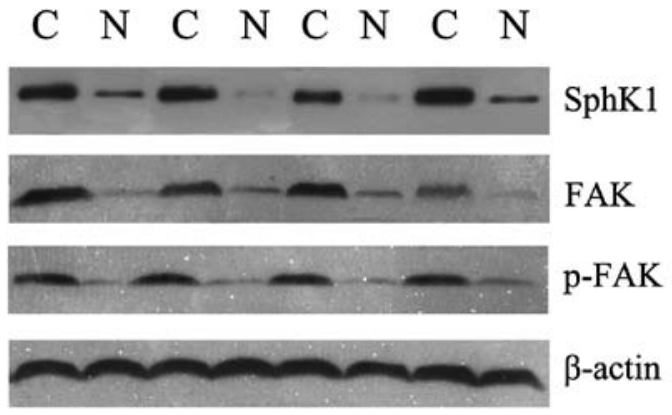

Figure 2. Western blot detection of SphK1, FAK and p-FAK in tissues from colon cancer and adjacent normal mucosa. Results shown are 4 representative paired tissues from patients with colon cancer. $\mathrm{C}$, cancer tissue; $\mathrm{N}$, normal mucosa tissue. The results of $\beta$-actin were used to confirm equal loading. The results shown are representative blotting of 3 independent experiments.

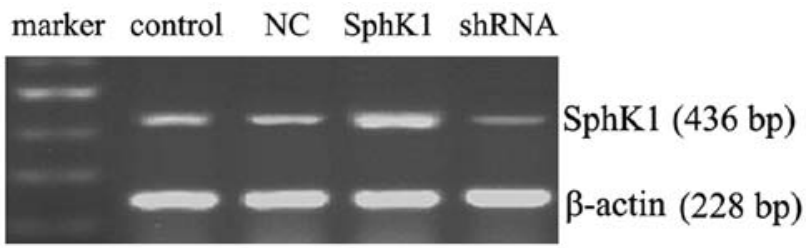

Figure 3. Effectiveness of SphK1 DNA, NC and SphK1 shRNA transfection. The mRNA expression in LOVO cells of different groups was detected utilizing RT-PCR. The RT-PCR results of $\beta$-actin were used to confirm equal loading. The results shown are representative blotting of 3 independent experiments.

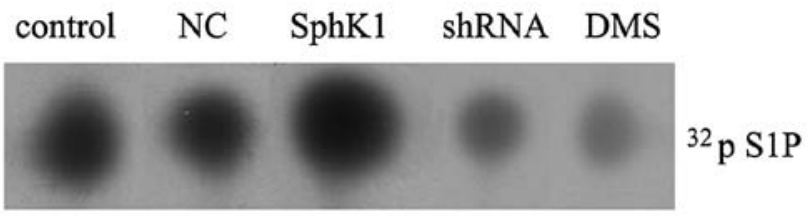

Figure 4 . SphK1 activity detected by autoradiography. SphK1 activity in LOVO cells of different group was measured by autoradiography, a representative TLC result was shown with labeled ${ }^{32} \mathrm{P}$ S1P level. The results shown are representative of 3 independent experiments.

expression of FAK, but also promoted the protein expression of FAK and p-FAK in tumor cells. In contrast, suppression of SphK1 by shRNA and DMS reduced the mRNA and protein 
Table II. Clinicopathologic characteristics and their association with SphK1, FAK and p-FAK expression.

\begin{tabular}{|c|c|c|c|c|c|c|c|}
\hline \multirow[b]{2}{*}{$\begin{array}{l}\text { Clinicopathologic } \\
\text { characteristics }\end{array}$} & \multirow[b]{2}{*}{$\mathrm{N}$} & \multicolumn{2}{|c|}{ SphK1 } & \multicolumn{2}{|c|}{ FAK } & \multicolumn{2}{|c|}{ p-FAK } \\
\hline & & $\begin{array}{l}\text { Positive } \\
\text { (\%) }\end{array}$ & $\mathrm{p}$-value & $\begin{array}{l}\text { Positive } \\
\text { (\%) }\end{array}$ & $\mathrm{p}$-value & $\begin{array}{l}\text { Positive } \\
\text { (\%) }\end{array}$ & p-value \\
\hline \multicolumn{8}{|l|}{ Gender } \\
\hline Male & 37 & $28(75.68)$ & 0.244 & $28(75.68)$ & 0.727 & $22(59.46)$ & 0.945 \\
\hline Female & 29 & $20(68.97)$ & & $23(79.31)$ & & $17(58.62)$ & \\
\hline \multicolumn{8}{|l|}{ Age } \\
\hline$\leq 50$ & 27 & $21(77.78)$ & 0.588 & $21(77.78)$ & 0.935 & $14(51.85)$ & 0.320 \\
\hline$>50$ & 39 & $27(69.23)$ & & $30(76.92)$ & & $25(64.10)$ & \\
\hline \multicolumn{8}{|l|}{ Histological grading } \\
\hline Well differentiated & 14 & $10(71.43)$ & 0.049 & $8(57.14)$ & 0.063 & $4(28.57)$ & 0.014 \\
\hline Moderately differentiated & 36 & $23(63.89)$ & & $28(77.78)$ & & $22(61.11)$ & \\
\hline Poorly differentiated & 16 & $15(93.75)$ & & $15(93.75)$ & & $13(81.25)$ & \\
\hline \multicolumn{8}{|l|}{ Dukes' stage } \\
\hline $\mathrm{A}$ and $\mathrm{B}$ & 34 & $21(61.76)$ & 0.039 & $22(64.71)$ & 0.012 & $15(44.12)$ & 0.011 \\
\hline $\mathrm{C}$ and $\mathrm{D}$ & 32 & $27(84.38)$ & & $29(90.63)$ & & $24(75.00)$ & \\
\hline \multicolumn{8}{|l|}{ Lymph node metastasis } \\
\hline Positive & 24 & $21(87.50)$ & 0.042 & $22(91.67)$ & 0.035 & $18(75.00)$ & 0.047 \\
\hline Negative & 42 & $27(64.29)$ & & $29(69.05)$ & & $21(50.00)$ & \\
\hline \multicolumn{8}{|l|}{ Distance metastasis } \\
\hline Positive & 20 & $18(90.00)$ & 0.038 & $19(95.00)$ & 0.023 & $16(80.00)$ & 0.023 \\
\hline Negative & 46 & $30(65.22)$ & & $32(69.57)$ & & $23(50.00)$ & \\
\hline Colon cancer tissues & 66 & $48(72.73)$ & 0.000 & $51(77.27)$ & 0.000 & $39(59.09)$ & 0.000 \\
\hline Normal colon tissues & 66 & $23(34.85)$ & & $15(22.73)$ & & $11(16.67)$ & \\
\hline
\end{tabular}
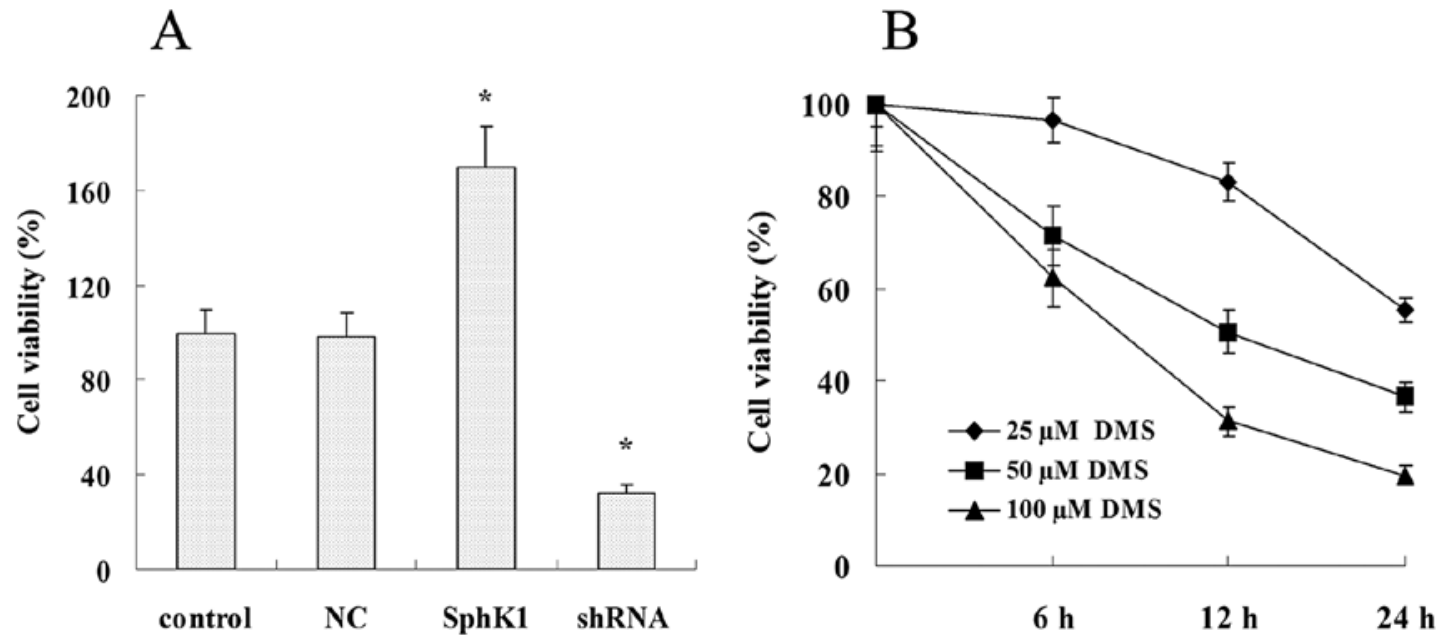

Figure 5. Effect of SphK1 on tumor cell proliferation. (A) Overexpression of SphK1 significantly enhanced the cell viability and suppression of SphK1 by SphK1 shRNA significantly suppressed the cell viability. (B) DMS suppressed the cell viability in a time- and dose-dependent manner. All results shown are the mean \pm SD of 3 independent experiments ( $\mathrm{p}<0.01$ vs. control group).

expression of FAK (Fig. 8). These results suggest that SphK1 may activate the FAK pathway in tumor cells.

SphK1 is required for the secretion and expression of ICAM-1 and VCAM-1 in LOVO cells. Fig. 9A shows that overexpression of SphK1 promoted the secretion of ICAM-1 and VCAM-1 in
LOVO cells, in contrast, the secretion of ICAM-1 and VCAM-1 was reduced with the suppression of SphK1 by DMS and shRNA. In addition, overexpression of SphK1 enhanced the protein expression of ICAM-1 and VCAM-1, suppression of SphK1 significantly reduced the protein expression of ICAM-1 and VCAM-1 (Fig. 9B). 

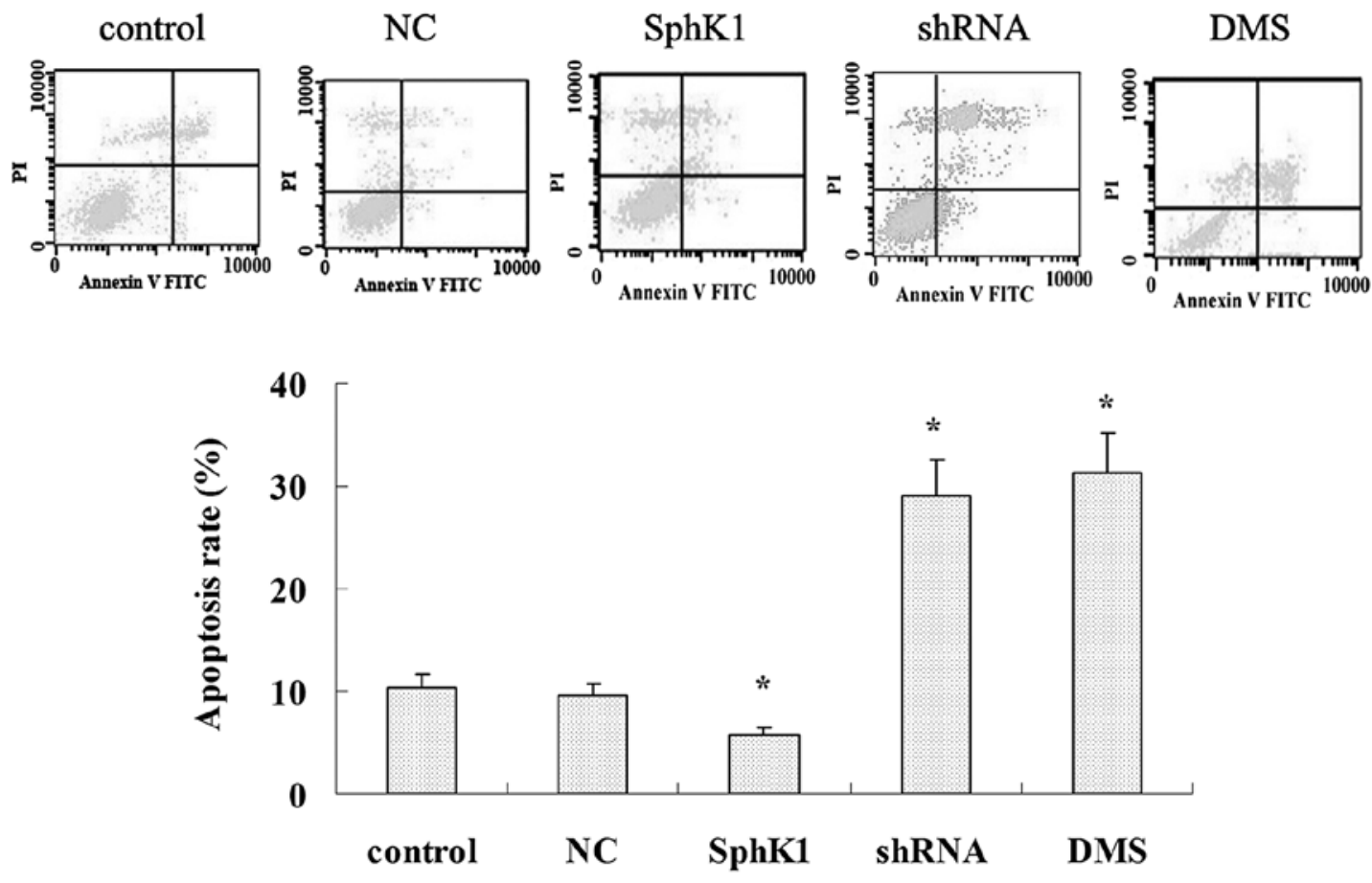

Figure 6. Effect of SphK1 on tumor cell apoptosis. Overexpression of SphK1 significantly suppressed cell apoptosis and suppression of SphK1 by SphK1 shRNA and DMS ( $50 \mu \mathrm{M}$ for $24 \mathrm{~h}$ ) significantly enhanced cell apoptosis. The data shown are the mean $\pm \mathrm{SD}$ of 3 independent experiments ("p $<0.01 \mathrm{vs.} \mathrm{control} \mathrm{group).}$

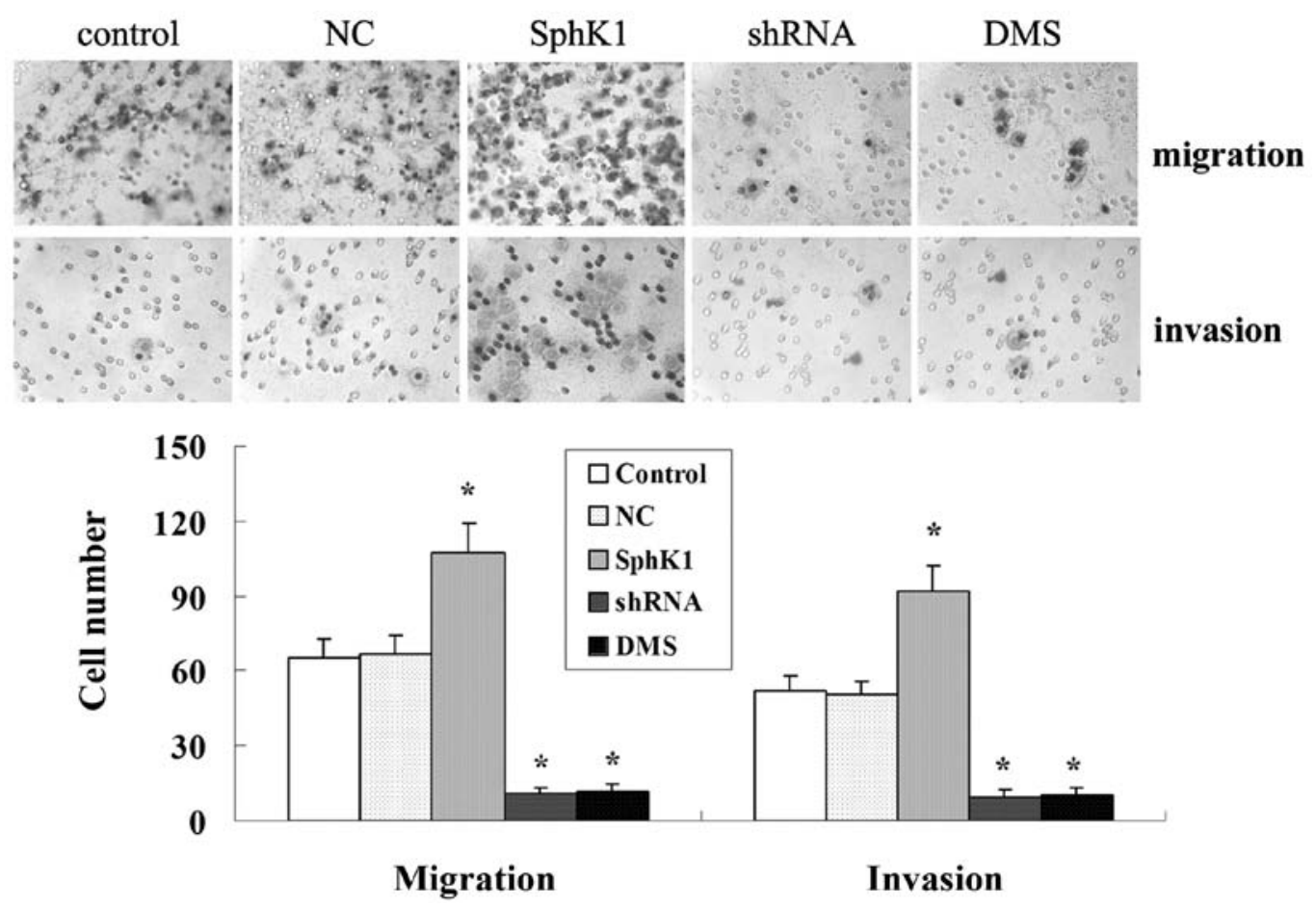

Figure 7. SphK1 promotes tumor cell migration and invasion. Overexpression of SphK1 significantly enhanced the cells penetrated through the porous membrane and suppression of SphK1 by SphK1 shRNA and DMS (50 $\mu \mathrm{M}$ for $24 \mathrm{~h})$ significantly reduced the cell penetrated through the porous membrane. The pictures are representative of cell penetration through the porous membrane (crystal violet staining, magnifications $\mathrm{x} 400$ ) and the data shown are the mean $\pm \mathrm{SD}$ of 3 independent experiments ( $\mathrm{p}<0.01$ vs. control group).

\section{Discussion}

Previous evidence indicated that SphK1 was an oncogenic enzyme and its activation was closely associated with angio- genesis, lymphangiogenesis, anti-apoptosis, transformation, proliferation and survival of tumor cells (19-21). Studies also showed the expression of SphK1 was enhanced in colon cancer (7). The present research confirmed this finding and 
A

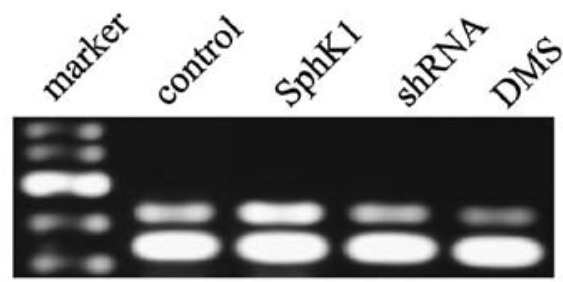

$\operatorname{FAK}(319 \mathrm{bp})$

$\beta$-actin (228 bp)
B control SphK1 shRNA DMS

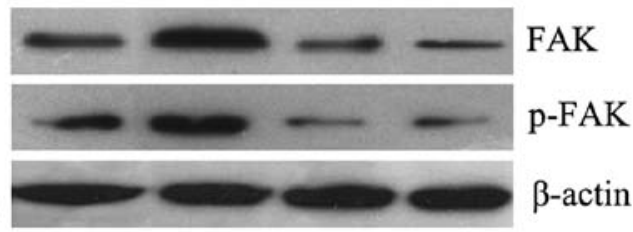

Figure 8. Effect of SphK1 on the expression of FAK and p-FAK in LOVO cells. (A) The FAK mRNA expression in LOVO cells of different groups was detected by RT-PCR and (B) the protein expression of FAK and p-FAK in LOVO cells of different group was detected by western blotting. The results of $\beta$-actin were used to confirm equal loading. Results are representative blotting of 3 independent experiments.

A

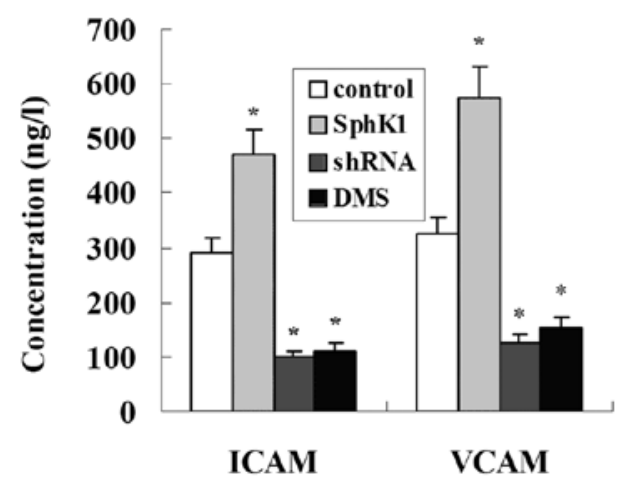

B

control SphK1 shRNA DMS

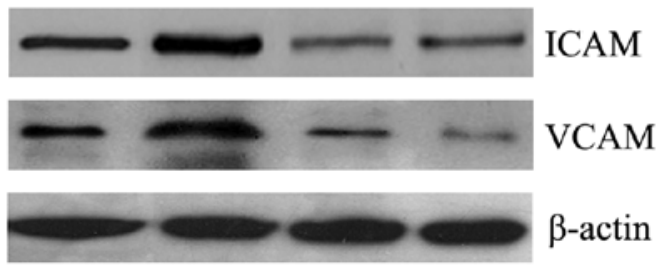

Figure 9. SphK1 enhances the secretion and expression of ICAM-1 and VCAM-1 in LOVO cells. The culture supernatant of SphK1, SphK1 shRNA and DMS $(50 \mu \mathrm{M}, 24 \mathrm{~h})$ group was collected for ICAM-1 and VCAM-1 detection using ELISA detection kits, the results shown (A) are the mean \pm SD from 3 independent experiments ( $\mathrm{p}<0.01$ vs. control group). The cells of different groups were harvested for western blot detection, the results shown (B) are representative of 3 independent western blot detection experiments, the results of $\beta$-actin were used to confirm equal loading.

demonstrated that SphK1 was overexpressed in colon cancer tissue but was absent or weakly expressed in normal colonic tissue. Moreover, the expression of SphK1 has been found to correlate with the Dukes' stage, histological grading, lymph node metastasis and distant metastasis. These results indicated that SphK1 may contribute to colon carcinogenesis and potentially also to metastasis of the malignancy phenotype. However, the molecular mechanisms of the tumor promoting activity of SphK1 remain to be determined.

Elevated FAK expression and activity is associated with malignancy in a variety of cancer cells, indicating FAK plays a critical role in tumor progression and metastasis $(22,23)$. Blocking phosphorylation of FAK not only inhibited the migration of pancreatic cancer cells but also reduced tumor growth, invasion and metastases in pancreatic cancer murine model (24). In the present investigation, enhanced expression of FAK and p-FAK (Tyr397) in colon cancer tissues was observed. The expression of FAK and p-FAK has been found to correlate with the Dukes' stage, lymph node metastasis and distant metastasis. These results also supported the role of FAK in progress of colon cancer (25). Moreover, the results of immunohistochemistry and western blot detection confirmed that the expression of SphK1 was closely related with the expression of FAK and p-FAK, which indicated that activation of FAK pathway may be regulated by SphK1 in the progression of colon cancer.
The co-expression of SphK1, FAK and p-FAK correlates with Dukes' stage, lymph node and distant metastasis of colon cancer supports the hypothesis that overexpression of SphK1 may promote the progression and confer malignancy phenotypes of colon cancer through FAK pathway activation. To confirm this hypothesis, the activity and expression of SphK1 was regulated in human colon cancer LOVO cells, results show that the expression of FAK and p-FAK were closely correlated with the activity and expression of SphK1, and suppressing SphK1 and FAK greatly inhibited the proliferation, migration and invasiveness of colon cancer cells. These results suggest the role of FAK pathway in SphK1-mediated malignancy phenotypes of colon cancer cells. However, further research should concentrate in filling the gap between SphK1 and FAK pathway and in exploring the events following FAK activation.

Cell adhesion molecules are involved in a variety of pathologies including carcinogenesis, particularly VCAM-1 and ICAM-1 play major roles in the initiation of tumor progression (26). Moreover, some reports indicated VCAM-1 and VCAM-1 were promising targets for the prevention and inhibition of tumor metastasis $(27,28)$. In patients with colorectal cancer, studies also show the serum levels of ICAM-1 and VCAM-1 were significantly higher than those of healthy controls and there was a significant association between the serum levels of these molecules, disease stage and the presence of both lymph node and distant metas- 
tases $(29,30)$. In the present study LOVO cells showed that the levels of ICAM-1 and VCAM-1 were upregulated with the overexpression of SphK1 and downregulated with the suppression of SphK1. These results indicated ICAM-1 and VCAM-1 were involved in SphK1 promoting the progression and conferring malignancy phenotypes of colon cancer cells. However, the exact mechanism of SphK1 regulating FAK, ICAM-1 and VCAM-1 need further investigation.

There is evidence that $\mathrm{S} 1 \mathrm{P}$ is a potent stimulator of VCAM-1 and ICAM-1 expression (31) and CCN6 enhanced the migration of chondrosarcoma cells by increasing ICAM-1 expression at least partly through the FAK signal pathway (32). In endothelial cells FAK was essential for induction of ICAM-1 and sVCAM-1-induced cell migration and was almost completely blocked by adenovirus containing FAK-related non-kinase (33). In human colon cancer, gastrin-releasing peptide was found to induce ICAM-1 via FAK and promoted tumor cell motility and attachment to the extracellular matrix (34). Collectively, these results indicate that the secretion and expression of ICAM-1 and VCAM-1 may be regulated by the FAK pathway. However, further studies in colon cancer cell lines and tissues are needed to validate this.

In summary, our results suggest that overexpression of SphK1 may be one of the mechanisms by which colon cancer gain malignancy phenotypes during malignant transformation. Furthermore, SphK1 may regulate VCAM-1 and ICAM-1 in a FAK pathway-dependent manner, which ultimately contributes to the tumor progression and malignancy phenotypes in colon cancer. SphK1 has potential as a therapeutic target in the antineoplastic treatment of colon cancer.

\section{Acknowledgements}

This study was supported by the National Natural Science Foundation of China (no. 30760275) and Natural Science Foundation from Guangxi Autonomous Region of China (no. 2011GXNSFA018182).

\section{References}

1. Jemal A, Siegel R, Xu J and Ward E: Cancer statistics, 2010. CA Cancer J Clin 60: 277-300, 2010.

2. Pitson SM: Regulation of sphingosine kinase and sphingolipid signaling. Trends Biochem Sci 36: 97-107, 2011.

3. Gamble JR, Sun WY, Li X, Hahn CN, Pitson SM, Vadas MA and Bonder CS: Sphingosine kinase-1 associates with integrin $\{$ alpha\} $\mathrm{V}\{$ beta\} 3 to mediate endothelial cell survival. Am J Pathol 175: 2217-2225, 2009.

4. Bergelin N, Blom T, Heikkilä J, et al: Sphingosine kinase as an oncogene: autocrine sphingosine 1-phosphate modulates ML-1 thyroid carcinoma cell migration by a mechanism dependent on protein kinase C-alpha and ERK1/2. Endocrinology 150: 2055-2063. 2009.

5. Li W, Yu CP, Xia JT, et al: Sphingosine kinase 1 is associated with gastric cancer progression and poor survival of patients. Clin Cancer Res 15: 1393-1399, 2009.

6. Pchejetski D, Doumerc N, Golzio M, et al: Chemosensitizing effects of sphingosine kinase-1 inhibition in prostate cancer cell and animal models. Mol Cancer Ther 7: 1836-1845, 2008.

7. Kawamori T, Kaneshiro T, Okumura M, et al: Role for sphingosine kinase 1 in colon carcinogenesis. FASEB J 23: 405-414, 2009.

8. Nemoto S, Nakamura M, Osawa Y, et al: Sphingosine kinase isoforms regulate oxaliplatin sensitivity of human colon cancer cells through ceramide accumulation and Akt activation. J Biol Chem 284: 10422-10432, 2009.
9. Wang H, Maurer BJ, Liu YY, et al: N-(4-Hydroxyphenyl) retinamide increases dihydroceramide and synergizes with dimethylsphingosine to enhance cancer cell killing. Mol Cancer Ther 7: 2967-2976, 2008.

10. Kohno M, Momoi M, Oo ML, et al: Intracellular role for sphingosine kinase 1 in intestinal adenoma cell proliferation. Mol Cell Biol 26: 7211-7223, 2006.

11. Schwock J, Dhani N and Hedley DW: Targeting focal adhesion kinase signaling in tumor growth and metastasis. Expert Opin Ther Targets 14: 77-94, 2010.

12. Hao HF, Naomoto Y, Bao XH, et al: Progress in researches about focal adhesion kinase in gastrointestinal tract. World J Gastroenterol 15: 5916-5923, 2009.

13. Leve F, Marcondes TG, Bastos LG, Rabello SV, Tanaka MN and Morgado-Díaz JA: Lysophosphatidic acid induces a migratory phenotype through a crosstalk between RhoA-Rock and Src-FAK signalling in colon cancer cells. Eur J Pharmacol 671: 7-17, 2011.

14. Dia VP and Gonzalez de Mejia E: Lunasin potentiates the effect of oxaliplatin preventing outgrowth of colon cancer metastasis, binds to $\alpha 5 \beta 1$ integrin and suppresses FAK/ERK/NF- $\kappa \mathrm{B}$ signaling. Cancer Lett 313: 167-180, 2011.

15. Zhao J, Singleton PA, Brown ME, Dudek SM and Garcia JG: Phosphotyrosine protein dynamics in cell membrane rafts of sphingosine-1-phosphate-stimulated human endothelium: role in barrier enhancement. Cell Signal 21: 1945-1960, 2009.

16. Lee OH, Lee DJ, Kim YM, Kim YS, Kwon HJ, Kim KW and Kwon YG: Sphingosine 1-phosphate stimulates tyrosine phosphorylation of focal adhesion kinase and chemotactic motility of endothelial cells via the $\mathrm{G}(\mathrm{i})$ protein-linked phospholipase C pathway. Biochem Biophys Res Commun 268: 47-53, 2000.

17. Gibbs TC, Rubio MV, Zhang Z, Xie Y, Kipp KR and Meier KE: Signal transduction responses to lysophosphatidic acid and sphingosine 1-phosphate in human prostate cancer cells. Prostate 69: 1493-1506, 2009.

18. Pettus BJ, Bielawski J, Porcelli AM, et al: The sphingosine kinase 1/sphingosine-1-phosphate pathway mediates COX-2 induction and PGE2 production in response to TNF-alpha. FASEB J 17: 1411-1421, 2003.

19. Cuvillier O, Ader I, Bouquerel P, Brizuela L, Malavaud B, Mazerolles C and Rischmann P: Activation of sphingosine kinase-1 in cancer: implications for therapeutic targeting. Curr Mol Pharmacol 3: 53-65, 2010.

20. Nagahashi M, Ramachandran S, Kim EY, et al: Sphingosine-1phosphate produced by sphingosine kinase 1 promotes breast cancer progression by stimulating angiogenesis and lymphangiogenesis. Cancer Res 72: 726-735, 2012.

21. Maceyka M, Harikumar KB, Milstien S and Spiegel S: Sphingosine-1-phosphate signaling and its role in disease. Trends Cell Biol 22: 50-60, 2012

22. Hao H, Naomoto Y, Bao X, Watanabe N, et al: Focal adhesion kinase as potential target for cancer therapy (Review). Oncol Rep 22: 973-979, 2009.

23. Lechertier $\mathrm{T}$ and Hodivala-Dilke K: Focal adhesion kinase and tumour angiogenesis. J Pathol 226: 404-412, 2012.

24. Stokes JB, Adair SJ, Slack-Davis JK, et al: Inhibition of focal adhesion kinase by PF-562,271 inhibits the growth and metastasis of pancreatic cancer concomitant with altering the tumor microenvironment. Mol Cancer Ther 10: 2135-2145, 2011.

25. Yu HG, Tong SL, Ding YM, et al: Enhanced expression of cholecystokinin-2 receptor promotes the progression of colon cancer through activation of focal adhesion kinase. Int J Cancer 119: 2724-2732, 2006.

26. Kobayashi H, Boelte KC and Lin PC: Endothelial cell adhesion molecules and cancer progression. Curr Med Chem 14: 377-386, 2007.

27. Shah N, Cabanillas F, McIntyre B, Feng L, et al: Prognostic value of serum CD44, intercellular adhesion molecule-1 and vascular cell adhesion molecule-1 levels in patients with indolent non-Hodgkin lymphomas. Leuk Lymphoma 53: 50-56, 2012.

28. Lu X, Mu E, Wei Y, Riethdorf S, et al: VCAM-1 promotes osteolytic expansion of indolent bone micrometastasis of breast cancer by engaging $\alpha 4 \beta 1$-positive osteoclast progenitors. Cancer Cell 20: 701-714, 2011.

29. Dymicka-Piekarska V, Guzinska-Ustymowicz K, Kuklinski A and Kemona H: Prognostic significance of adhesion molecules (sICAM-1, sVCAM-1) and VEGF in colorectal cancer patients. Thromb Res 129: e47-e50, 2012. 
30. Alexiou D, Karayiannakis AJ, Syrigos KN,Zbar A, Kremmyda A Bramis I and Tsigris C: Serum levels of E-selectin, ICAM-1 and VCAM-1 in colorectal cancer patients: correlations with clinicopathological features, patient survival and tumour surgery. Eur J Cancer 37: 2392-2397, 2001.

31. Kase H, Hattori Y, Jojima T, et al: Globular adiponectin induces adhesion molecule expression through the sphingosine kinase pathway in vascular endothelial cells. Life Sci 81: 939-943, 2007.

32. Fong YC, Lin CY, Su YC, et al: CCN6 enhances ICAM-1 expression and cell motility in human chondrosarcoma cells. J Cell Physiol 227: 223-232, 2012.
33. Petzold T, Orr AW, Hahn C, Jhaveri KA, Parsons JT and Schwartz MA: Focal adhesion kinase modulates activation of NF-kappaB by flow in endothelial cells. Am J Physiol Cell Physiol 297: C814-C822, 2009.

34. Taglia L, Matusiak D, Matkowskyj KA and Benya RV: Gastrinreleasing peptide mediates its morphogenic properties in human colon cancer by upregulating intracellular adhesion protein-1 (ICAM-1) via focal adhesion kinase. Am J Physiol Gastrointest Liver Physiol 292: G182-G190, 2007. 